\title{
Impact of Logistics Outsourcing Strategy in Oil and Gas Industry in Uganda
}

\author{
Augustine Muhindo ${ }^{1}$, Jian Zhou ${ }^{1} \&$ Maureen Kapute Mzuza ${ }^{2}$ \\ ${ }^{1}$ School of Management, Shanghai University, P. R. China \\ ${ }^{2}$ State Key Lab of Estuarine, East China University, P. R. China \\ Correspondence: Jian Zhou, School of Management, Shanghai University, Shanghai 200444, P. R. China. \\ E-mail: zhou_jian@shu.edu.cn
}

Received: March 21, 2013

Accepted: May 8, 2014

Online Published: May 22, 2014

doi:10.5539/ijbm.v9n6p187

URL: http://dx.doi.org/10.5539/ijbm.v9n6p187

\begin{abstract}
The purpose of the study is to analyze the impact of logistics outsourcing strategy in the oil and gas industry in Uganda. The most outstanding benefit is that, companies outsourced their logistics activities to restructure their distribution networks and achieve competitive advantage. For this purpose purposive sampling method is used where qualitative data are collected and interpreted. Primary data are collected using research questionnaires where quantitative method is used in data presentation and analysis of the impact of logistics outsourcing strategy in the oil and gas industry. The research findings reveal that there are many benefits resulting from using logistics outsourcing strategy in the oil and gas industry and in the same way, challenges are faced by both oil and gas companies and logistics service providers in executing business contracts. Solutions are pursued to create an environment for the oil and gas industry and the third party logistics services providers to achieve a common goal. Findings show that it is very important to outsource full or part of logistics activities to logistics service providers in order to attain competitive advantage. Logistics outsourcing strategy plays an important role in the business especially in minimizing operating costs and spreading risk between the parties engaged in business contracts. Therefore it is necessary for company managers to check their strategies to make sure that logistics activities are in place.
\end{abstract}

Keywords: logistics outsourcing, logistics service provider, oil and gas company, supply chain management

\section{Introduction}

According to Sink and Langley (1997), outsourcing is a business strategy that a company gives its inner non-core activities to external service providers to facilitate company control over their resources and share risks. Additionally, Mohiuddin and Su (2013b) defines the term outsourcing as acquiring of components or services from outside sources rather than producing in-house. The principal company only focuses on core matters necessary to survival and growth. This strategy encompasses outsourcing and relocating to low cost suppliers from advanced firms in order to lower entire costs of production by realizing benefits from competitive factors of production and gain more profits. Several firms have changed to logistics outsourcing as business strategy to restructure their dissemination network and gain competitive advantage. In addition to that, logistics outsourcing can also be defined as the use of third party logistics provider in full or part of the organization's logistics activities. This strategy has been applied by many firms for long time now and it is therefore noted that firms which has embraced outsourcing as the number one strategy have accessed cheaper inputs from specialized firms eventually leading to restructuring of production (Mohiuddin \& Su, 2013a). The strategy has progressively become an effective means of minimizing logistics costs. Data shows that almost $60 \%$ of 500 progressive companies use a third party logistics provider to perform their in-house activities.

In the era of business reforms, many firms adopted outsourcing strategy to forge away in altering business operations and retain core activities to achieve competitive advantage. Firms that restructure their supply chain network have fundamentally involved the reconfiguration of their logistics activities which involves transportation, storage, forwarding, warehousing and value addition services like packaging and labeling (Barret, 1982; Cooper \& Kaplan, 1991). Quélin and Duhamel (2003) argued that for the past 20 years, outsourcing of logistics activities has been one of the most used services in many companies. Companies that used this new strategy of using third party logistics scored greater logistics performances instead of sourcing them from within. 
According to Shepherd (2011) and Freytag et al. (2012), the decision made by oil and gas companies on whether to outsource logistics activities or not, depend on make or buy decisions. Similarly, literatures show that 3PLs outsourcing is extensively popular in Europe (Mckinnon, 1999; Chima, 2007), North America (Cooper \& Kaplan, 1991) and Asia Pacific region (Zhao \& Tang, 2009). On the other hand, there is less information available on 3PL outsourcing especially in developing regions including Africa. Globalization forces together with institutional and structural reforms that are developing in Africa pledge for a fast-tracked economic improvement and opportunities in the continent. With its aggressive tracking of economic and political integration, East Africa is one of the regions with such gigantic development potential (Golooba-Mutebi, 2003; Kenyon \& Meixell, 2011; Ahimbisibwe et al., 2012). Like other regions in Africa, it is rich in minerals and other natural resources. This makes it not only a critical source of raw materials for different industries but also a common market for local and global companies. As business networks grow and complexities in operations increases it is absolutely important to understand challenges of doing business in the region. For firms aspiring to enter this market, it is imperative to get hold of this understanding and up to date knowledge on how to achieve relevant and finest logistic capabilities in the region (Zhou \& Liu, 2003 \& 2007; Cheong, 2004; Sonmez \& Lim, 2012). Guasch and Kogan (2001) defined strategic outsourcing as an inventiveness to build competitive advantage from original suppliers involved in product manufacturing, sharing of supplier technology and supplier assistance in product development, service and process improvements. In line with the above, Strategic outsourcing can also be described as a way to obtain capabilities without investments and the principal objectives are to lessen uncertainty and improve flexibilities (Levy, 1995; Weidenbaum, 2005; Hofmann \& Belin, 2011). It is worth noted that, firms which embraces this strategy reap numerous benefits from competitive advantages in form of reduced-costs-increased value factors of production and business networking and thereby helping them to join a fresh market in the take-off stage of the industry (Mohiuddin \& Su, 2013b).

In relation to above, there is a need to build a very sophisticated supply chain that can create smooth flow of information, goods and services from inbound and outbound for the purposes of achieving high customer service delivery resulting into high performance results (Sitek \& Wikarek, 2012). The main objective of supply chain management (SCM) is to stimulate sales, minimize costs and take full advantage of business assets by refining collaboration and communication between all the actors creating the supply chain (Chopra \& Meindl, 2009). This gives a clear description of real business gains as results of interdependence amongst firms characterized by increased trade in transitional goods or services and technical know-how as well as production network (Mohiuddin \& Su, 2013a).The supply chain management is a decision process that not only integrates all of its participants but also helps to coordinate the basic flows: products/services, information and funds (Hofmann \& Belin, 2011; Sitek \& Wikarek, 2012; Zhou et al., 2013). Changes in the global economy and the increasing globalization lead to the widespread use of IT tools, which enables continuous, real time communication between the supply chain links (Lee et al., 2012). One major objective is to analyze the impact of logistics outsourcing strategy and assign it to specialized companies (Sitek \& Wikarek, 2012).

This trend is assisted to the advancement of logistics outsourced operators known as 3PL. The term 3PL refers to the use of external companies and organizations to carry out logistic functions that can involve the entire logistics process or its selected features (De Boer et al., 2006; Kenyon \& Meixell, 2011). The company offers and provides 3PL services using its own means of transport, warehouses, equipment and other necessary resources, and acts as a "third party" between a producer and a customer (Mello et al, 2008). The resulting model with the supply chain logistics services outsourced to a specialized 3LP companies is shown in Figure 1. This kind of cooperation is frequently referred to as the logistics alliance. 


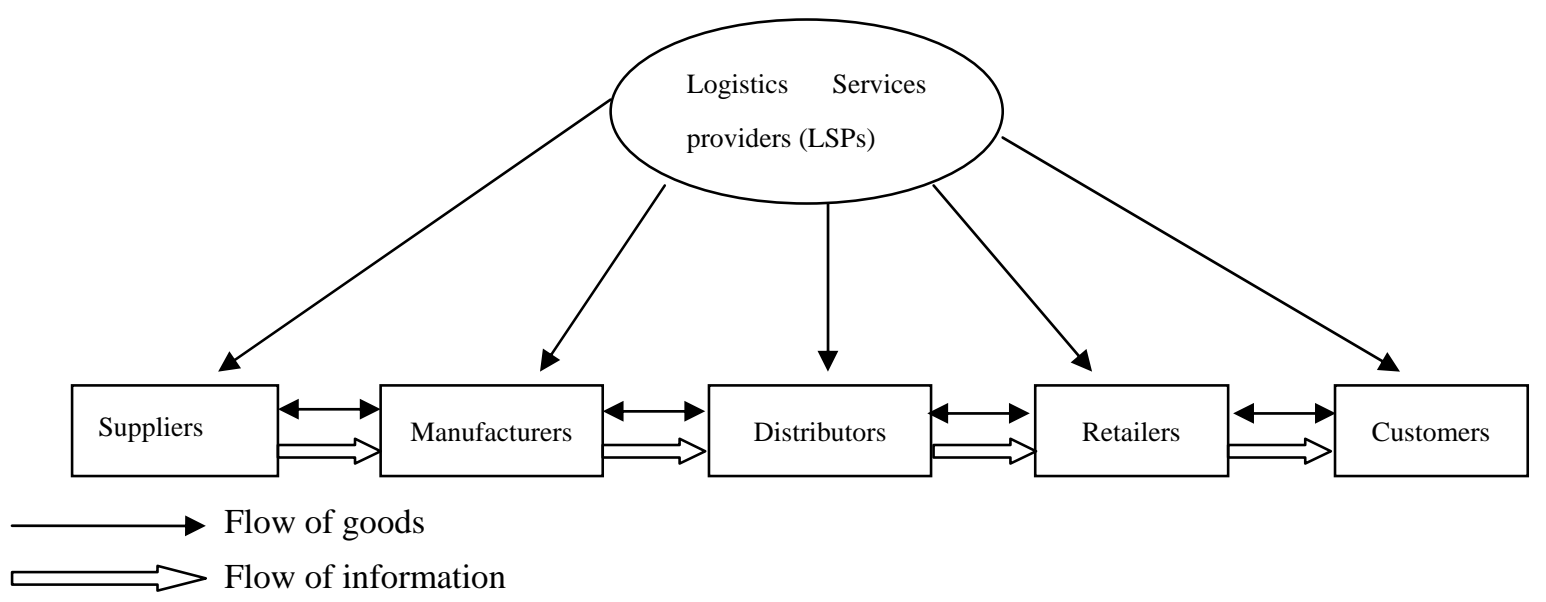

Figure 1. Conceptual model of supply chain showing flow of goods and information

Figure 1 shows the flow of information right from LSPs to suppliers transmitted via manufacturers, distributors, retailers and then to customers. These receiving ends (inbound and outbound) of information from LSP share information amongst themselves for purposes of reducing lead time, and improving customer relationships. It should be noted that movement of good or service is dispatched or received in way that delays are completely eliminated, hence achieving competitive advantage. In same way, goods flow from where they are produced in raw materials (suppliers), through manufacturers (transforms raw materials to semi-finished and finished) to distributors through retailers to final customers who are the end users of the product or service.

Studies also have covered a wide range of industries including general manufacturing, mineral exploration, consumer goods, traditional retail, and online (e-commerce) retail (Chima, 2007; Lee et al., 2012). However, there are many literatures written on oil and gas but only few or no literature is available on 3PL outsourcing of oil and gas industry in Uganda. Therefore this paper focused on analysis of the impact of logistics outsourcing strategy in the oil and gas industry in Uganda.

\section{Research Design}

Data was collect from both oil and gas companies and LSPs from centrally and suburb of Kampala city, Uganda. The research initially adopted a purposive sampling, as it involved engaging participants likely to provide relevant information regarding research questions. Then, within the group of desired respondents, individual companies were randomly selected. This was done to ensure that each one of the respondents had an equal chance of being selected. As for the managers, the researcher intended to speak with all of them but others were not available.

Qualitative research was generally used in this study, as words were emphasized in the process of data collection and interpretation, contrary to numbers as is the case with quantitative method. However, some strands of quantitative research have also been applied in the analysis and presentation of results. The researcher administered two types of questionnaires to oil and gas companies, and to logistics outsourcing service providers. A total of 5 oil and gas companies and 3 logistics service providers responded to the questionnaires. The study used both questionnaires and in-depth interview. The questionnaires were administered to Managing Directors, Logistics Managers, Procurement Officers and Production Managers. These questionnaires generally comprised demographic characteristics, educational qualifications, company category. They also contained an open-ended question. 
Table 1. Number of managers representing companies in answering research questionnaires

\begin{tabular}{|c|c|c|c|c|}
\hline Name of company & $\begin{array}{l}\text { Manager/ } \\
\text { CEO }\end{array}$ & Category & $\begin{array}{l}\text { Number of male } \\
\text { employee }\end{array}$ & $\begin{array}{l}\text { Number of } \\
\text { female employee }\end{array}$ \\
\hline 1. SDV Transami & 1 & Logistics & 185 & 350 \\
\hline 2. Bemuga & 1 & Logistics & 40 & 15 \\
\hline 3. Shell/VIVO Energy Uganda Ltd & 1 & Oil and gas & 70 & 35 \\
\hline 4. Richflo Logistics Ltd & 1 & Logistics & 65 & 15 \\
\hline 5. Pearls Oil Uganda & 1 & Oil and gas & 210 & 55 \\
\hline 6. Habib Oil Uganda & 1 & Oil and gas & 270 & 80 \\
\hline 7. Total Uganda & 1 & Oil and gas & 750 & 340 \\
\hline 8. Heritage Oils & 1 & Oil and gas & 120 & 43 \\
\hline Totals & 8 & N/A & 1710 & 933 \\
\hline
\end{tabular}

The number of managers representing companies in answering research questionnaires in this study has been summarized in Table 1. It is clearly shown that Total Uganda has the biggest number of employees with 1090, followed by SDV Transami 535, Habib 350, Pearls Uganda 265, Heritage Uganda 163, Shell/VIVO energy Uganda ltd 105, Richflo Logistics ltd 80, and Bemuga 55 employees. And this is graphically shown in Figure 2 combining both oil \& gas companies and logistics service providers.

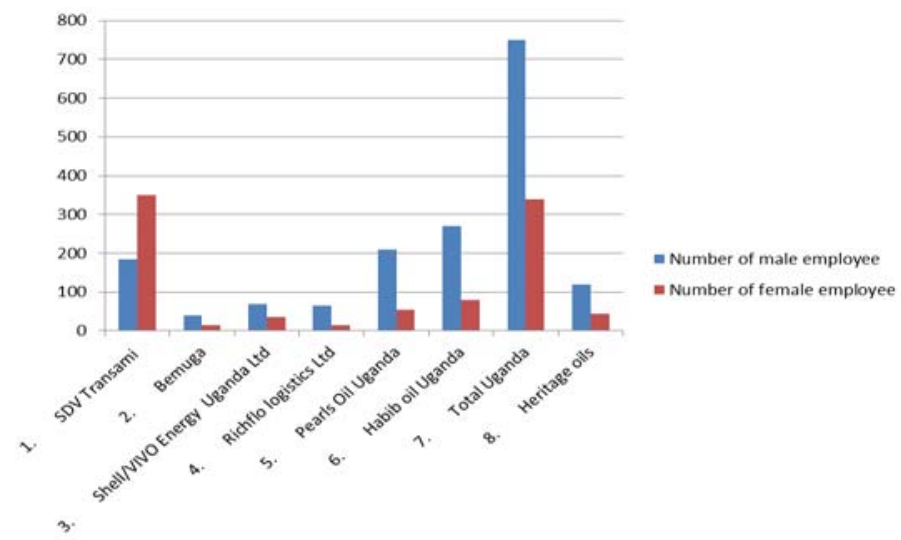

Figure 2. Number of managers representing companies in answering research questionnaires

\section{Survey Results}

The data collected from in-depth interviews and mailed survey sources were analyzed to answer the intended research questions. This section begins with a description of the respondents' characteristics. This would be followed by the presentation of the respondents' perceptions about how company manager ensures customer service delivery by achieving competitive advantage over the others. Later in this section, an analysis of each of the items on the questionnaires and the in-depth interview will be provided.

\subsection{Characteristics of Respondents}

This section describes the demographic characteristics of the respondents. These characteristics, which included gender and highest academic qualification, are more detailed in Table 2.

Table 2. Gender and highest academic qualification of respondents

\begin{tabular}{lll}
\hline Respondents characteristics & Total number & Percentage (\%) \\
\hline Male employees & 1710 & 65 \\
Female employees & 933 & 35 \\
Qualification-Degree (Company manager representatives) & 8 & 100 \\
\hline
\end{tabular}

The results shown in Table 2 indicate that $65 \%$ were male employees while $35 \%$ were females; $100 \%$ of the managers who represented their companies were all male. It also indicates that $100 \%$ of the company managers 
have degrees and companies employ at least $65 \%$ male and $35 \%$ female in different category of oil \& gas and logistics service providers. It is shown in Table 1 that out of 8 companies that participated in the research, 3 are logistics service providers while 5 are oil and gas companies. According to the Ministry of trade and industry, these companies are qualified to operate legally and employee suitable candidate of high qualification trained in field of business management.

3.2 Respondents' Perception on Analysis of the Impact of Logistics Outsourcing Strategy on the Logistics Performance in the Oil and Gas Industry

This section of the study provides a descriptive statistics of each of the two variables studied in the research. The responses were categorized into four levels, and these were "strongly disagree", "disagree”, "agree” and "strongly agree". However, for purposes of interpretation, some response categories were combined and they include; those of strongly agree, agree, strongly disagree, and disagree. Table 3 shows oil and gas managers' perception about the impact of logistics outsourcing strategy on the logistics performance in the oil and gas industry in Uganda.

After administering the questionnaires to company managers, the collected results generally showed that most factors were considered highly by oil and gas companies when selecting LSPs as shown in Table 3.

Table 3. Managers’ perception about factors considered when selecting LSPs

\begin{tabular}{lllll}
\hline Factors & Strongly agree & Agree & Disagree & Strongly disagree \\
\hline Service quality & 4 & 1 & 0 & 0 \\
Service price & 3 & 1 & 1 & 0 \\
Continuous improvement & 3 & 1 & 0 & 0 \\
Business cope and market & 2 & 2 & 1 & 0 \\
Professional and staff & 3 & 2 & 0 & 0 \\
Suitable IT system & 3 & 2 & 0 & 0 \\
Culture and strategy & 2 & 0 & 0 & 0 \\
Supporting business expansion & 3 & 2 & 0 & 0 \\
\hline
\end{tabular}

In Table 3, almost of the responses agreed that service quality, continuous improvement and supporting business expansion need to be considered when choosing LSPs. For example, 4 out of 5 managers believe that service quality is priority, 4 believe that service price should be considered seriously as compared to 1 manager who completely disagreed. In addition to that, factors like professional \& staff, suitable IT system, culture and strategy and supporting business expansion were considered in selecting the best service providers. The overall figures show responses about factors considered when selecting LSPs are shown in Figure 3.

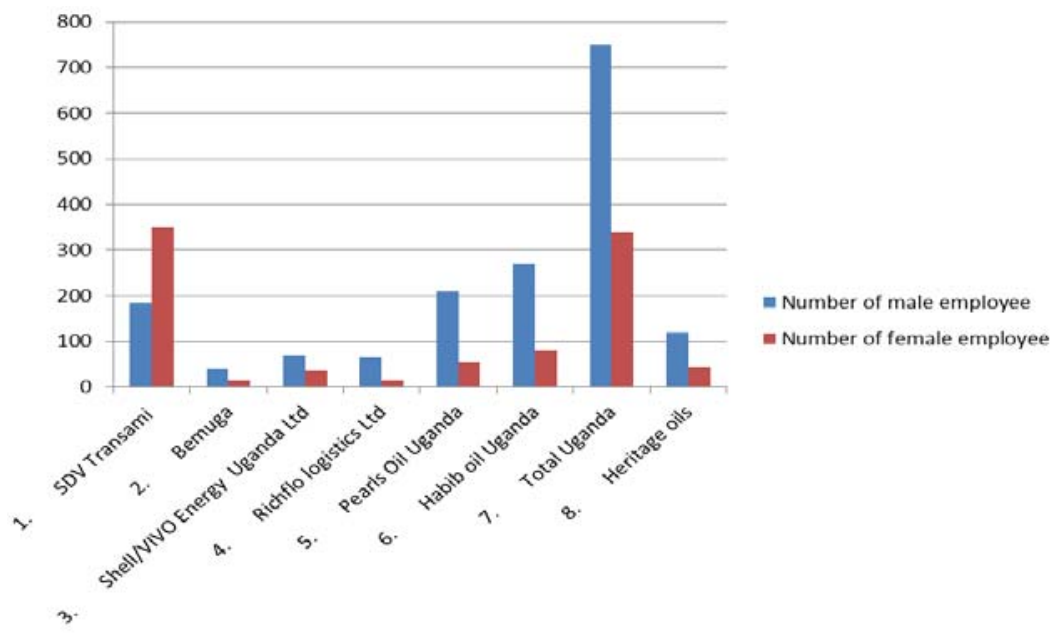

Figure 3. Managers' perception about factors considered when selecting LSPs 
3.3 Managers' Perception about Benefits Resulted from Embracing Outsourcing Strategy in Realizing Logistics Performance in the Oil and Gas Industry

Table 4. Managers' perception about benefits resulting from embracing outsourcing strategy in realizing logistics performance in oil and gas industry

\begin{tabular}{lllll}
\hline Benefits & Strongly agree & Agree & Disagree & Strongly disagree \\
\hline Elimination of infrastructure investments & 2 & 1 & 1 & 1 \\
Access to world class process, products, & 3 & 2 & 0 & 0 \\
services or technology & 3 & 2 & 0 & 0 \\
Risk sharing & 3 & 2 & 0 & 0 \\
Reducing operating costs & 5 & 0 & 0 & 0 \\
Better cash flow & 1 & 2 & 2 & 0 \\
Exchanging fixed cost with variable costs & & & & \\
\hline
\end{tabular}

Table 4 shows managers' response regarding benefits of logistics outsourcing strategy. It is be shown that 3 managers agreed that elimination of infrastructure investments will benefit oil and gas companies as one of outsourcing strategy while 2 managers disagreed with that idea. For instance, all 5 managers vigorously agreed that access to world class process; product, service or technology, risk sharing, reducing operating costs and better cash flow are among the few benefits that resulted from embracing logistics outsourcing strategy. It is also noted that 3 out of 5 managers agreed that exchanging fixed costs with variable costs could boost company performance whereas 2 managers disagreed. These overall responses are displayed in Figure 4 respect with numbers of managers.

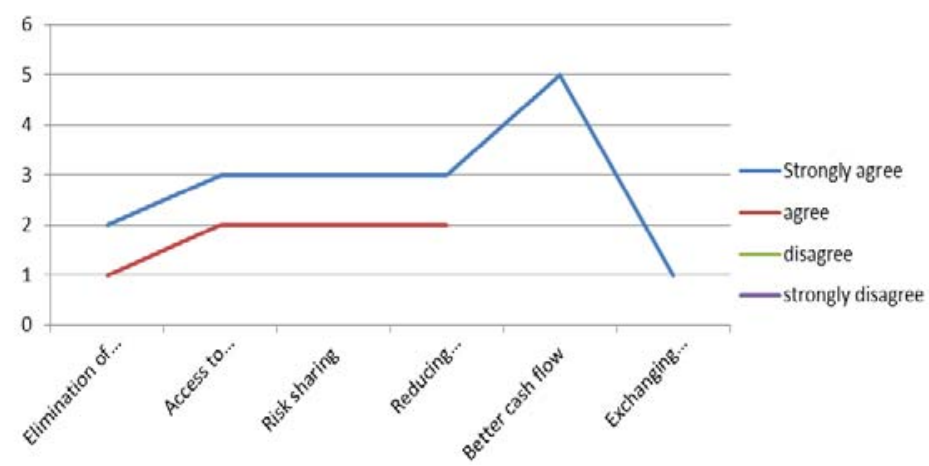

Figure 4. Managers' perception about benefits resulting from embracing outsourcing strategyin realizing logistics performance in oil and gas industry

\subsection{Managers' Perception about Challenges Faced When Dealing with 3PLs}

Table 5. Managers' perception about challenges faced while dealing with 3PLs in meeting desired performance results

\begin{tabular}{lllll}
\hline Challenges faced & Strongly agreed & Agree & Disagree & Strongly disagree \\
\hline Possibility of inefficient Management & 2 & 3 & 0 & 0 \\
Conflict of firms culture & 2 & 2 & 1 & 0 \\
Latent information asymmetry & 2 & 2 & 1 & 0 \\
Loss of control over third party logistics & 3 & 1 & 1 & 0 \\
provider & 3 & 2 & 0 & 0 \\
Hidden costs & 4 & 0 & 1 & 0 \\
Loss of logistics innovative capacity & & & \\
\hline
\end{tabular}


The responses in Table 5 show that generally the oil and gas companies face many challenges when dealing with third parties service providers. This is confirmed in Table 5, whereby 4 of the 5 company managers agreed that these challenges were faced while dealing with third parties logistics providers hence a bottleneck to achieving competitive advantage.

\subsection{Managers' Perception about How to Overcome Challenges Faced}

After collecting and analyzing the data regarding manager's perception about how to overcome challenges faced, the results are shown in Table 6 .

Table 6. Managers’ perception about how to over challenges faced

\begin{tabular}{lllll}
\hline Remedies & Strongly agree & Agree & Disagree & Strongly disagree \\
\hline Performance indices for logistics outsourcing & 2 & 2 & 0 & 1 \\
Information sharing encouragement mechanism & 3 & 1 & 1 & 0 \\
Suitable performance tactic & 3 & 2 & 0 & 0 \\
Customer relationship management & 0 & 0 & 0 & 0 \\
\hline
\end{tabular}

The trend of responses in Table 6 is that manager believes these remedies like customer relationship management and suitable can lead to positive change in the companies' performance to achieve competitive advantages and high customer service delivery while aiming at low logistics costs. It is also noted that 4 company managers agreed that performance indices for logistics outsourcing was a remedy not to be left out while 1 manager disagreed with the idea. The overall figures showing responses on how to overcome challenges faced are shown in Table 6.

\subsection{Logistics Managers’ Perception about Services Provided to Oil and Gas Companies}

Logistics managers' questionnaire comprised of 3 questions regarding on how to deal with oil and gas companies in Uganda. The findings are shown in Table 7.

Table 7. Logistics managers’ perception about services provided to oil and gas companies

\begin{tabular}{lllll}
\hline Services & Strongly agree & Agree & Disagree & Strongly disagree \\
\hline Inbound and outbound transportation & 2 & 1 & 0 & 0 \\
Door-to-door transportation services & 0 & 2 & 1 & 0 \\
Documentation handling & 0 & 1 & 2 & 0 \\
Tracking and tracing information & 2 & 1 & 0 & 0 \\
Delivery performance tools & 0 & 1 & 2 & 0 \\
\hline
\end{tabular}

Findings show that all of the 3 outsourcing mangers agreed that they provide services to oil and gas companies. Managers also affirmed that because of positive relationship exiting between them, there is efficient service delivery based on mutual understanding. It is also found out that documentation handling, tracking and tracing information and delivery performance tools were the most common services offered by logistics service providers.

\subsection{Logistics Managers' Perception about Challenges Encountered in the Process of Executing Business} Contract

Table 8. Logistics managers' perception about challenges encountered in the process of executing business contract

\begin{tabular}{lllll}
\hline Challenges & Strongly agree & Agree & Disagree & Strongly disagree \\
\hline The possibility of inefficient management & 2 & 0 & 1 & 0 \\
Conflicts of firm culture & 1 & 0 & 2 & 0 \\
Latent information asymmetry & 1 & 2 & 0 & 0 \\
Loss of control over third party logistics & 1 & 2 & 0 & 0 \\
provider & 3 & 0 & 0 & 0 \\
Hidden costs & 2 & 1 & 0 & 0 \\
Loss of logistics innovative capacity & & & \\
\hline
\end{tabular}


Table 8 generally reveals that 2 out of 3 managers agreed while the other 1 disagreed on the possibility of unproductive management of logistics activities. $100 \%$ of the respondents indicate that conflict of firm culture, latent information asymmetry, control over third party logistics providers is forfeited, hidden costs and loss of logistics innovative capacity are the biggest challenges faced by logistics companies to execute logistics activities efficiently.

3.8 Logistics Managers' Perception about What can be Done to Overcome Challenges in Carrying out Logistics Activities in the Oil and Gas Companies

Table 9. Logistics managers' perception on how to overcome challenges faced in executing logistics activities in the oil and gas companies

\begin{tabular}{lllll}
\hline Remedies & Strongly agree & Agree & Disagree & Strongly disagree \\
\hline Performance indices for Logistics outsourcing & 2 & 1 & 0 & 0 \\
Information sharing encouragement mechanisms & 2 & 0 & 1 & 0 \\
Suitable performance tactic & 2 & 1 & 0 & 0 \\
Customer relationship management & 3 & 0 & 0 & 0 \\
\hline
\end{tabular}

The trend of responses in Table 9 is that managers believe these remedies like customer relationship management and suitable performance tactic can make positive change in the companies' performance in achieving competitive advantages and high customer service delivery while aiming at lowering logistics costs. Even though, the trend is like this, a substantial number of respondents 2 out of 3 managers agreed with performance indices for logistics outsourcing while 1 disagreed for being supportive in fostering logistics performance.

\section{Analysis and Discussion}

\subsection{Table 3: Managers' Perception about Factors Considered When Selecting LSPs}

From Table 3 of the findings, managers agreed that factors like service quality, service price, business cope \& market continuous, professional \& staff, improvement and support business expansion are the key factors in selecting logistics service providers to perform non-core activities that would have been performed in-house (Mckinnon, 1999; Kenyon \& Meixell, 2011). This shows that, oil and gas companies, do not solely own logistics activities that is why by outsourcing most of the company activities, logistics costs are minimized to optimal level. These factors are categorized into strategic, operational, financial and environmental. It is ideally noted that for a successful oil and gas company to achieve higher performance results, factors must be considered seriously and be implemented by all participating parties in provision of cost-effective services at a quality level competitive in the market (Mohiuddin, 2010; Gray et al., 2013).

\subsection{Table 4: Managers' Perception about Benefits Resulting from Embracing Outsourcing Strategy}

There are several arguments as to why companies outsource their logistics activities to service providers and these arguments were on the basis of the benefits that may result from the strategy. These benefits include elimination of infrastructure investments; this was equally supported by 3 managers, who agreed that by using outsourcing strategy may lead to lower expenses in assets investment by relying on others with better infrastructures as noted by (Weidenbaum, 2005). Other benefits include; access to world class process, product, service or technology, risk sharing, recuing operating costs and better cash flow among others that were vigorously agreed by all the 5 managers as benefits embraced from the strategy (Quélin \& Duhamel, 2003; Freytag et al., 2012). To augment these benefits, risk is spread across companies in the process of diversifying businesses along the existing ones, hence high level of coordination and synchronization of business relationship.

\subsection{Table 5: Managers' Perception about Challenges Faced While Dealing with 3PLs}

The two parties in the deal (the principal and the provider) keep their autonomy while being significantly in a state of mutual dependence. The identity of the two parties is important because neither can be replaced without generating costs. However the principal which is the oil and gas company in this case shows that it faces some challenges while dealing with service providers and the challenges include; the possibility of unproductive management, conflicts of firm culture, latent information asymmetry, control over third parties logistics providers being forfeited, hidden costs and loss of logistics innovative capacities (Weidenbaum, 2005; Mello et al., 2008; Zhao \& Tang, 2009; Shepherd, 2011).This form of governance requires quite range of tolerance from 
both parties and this seem to be a fear as evidenced from findings in Table 5 that 4 out of the 5 managers agreed that these challenges were really a bottleneck in achieving logistics performance.

\subsection{Table 6: Managers' Perception about How to Overcome Challenges Faced}

From the trend of findings in Table 7 solutions are sought in regard to overcome challenges faced by the oil and gas companies. Chima (2007), Cheong (2004), Ahimbisibwe et al (2012) indicated that performance indices for logistics outsourcing and customer relationship management as solutions to overcome challenges as it has been supported by 4 managers to the impeding challenges which could have led to low performance levels in the oil and gas industry. The most important remedy is customer relationship management as shown in Table 6 which triggers customer service delivery and lows lead time since managers and employees can easily access most recent data immediately about customers need whenever they need (Logan, 2000).

\subsection{Table 7: Logistics Managers' Perception about Services Provided to Oil and Gas Companies in Uganda}

Analysis is made in respect with services provided to oil and gas companies by logistics service providers. These include documentation handling, transportation services among others (Chopra \& Meindl, 2009, Chima, 2007, Persson \& Virum, 2001). Work is spread across companies involved to lessen lead time, hence leading to efficient customer service delivery. This was evidenced from the findings in Table 7 where all managers agreed that they provide services to oil and gas companies. It is observed that, services provided by LSPs are standardized and contracts are executed both efficiently and effectively.

\subsection{Table 8: Logistics Managers' Perception about Challenges Encountered}

Belcourt (2006) and Cheong (2004) noted that the possibility of inefficient management and latent information asymmetry are one the few clear challenges faced by logistics service providers in the process of executing business contracts to principal companies. Research findings show that 2 out of 3managers agreed while other 1 disagreed on possibility of inefficient management of logistics activities. This is very clear phenomenon that without efficient relationship management between two parties in business contract, delays in material and information flow will occur, hence leading to company losses (Cheong, 2004).

\subsection{Table 9: Logistics Managers' Perception on How to Overcome Challenges Faced}

The managers were given a chance to choose which solutions could be paramount in overcoming challenges faced in executing logistics activities in the oil and gas companies. All the responses are organized in Table 9 where managers came up with some remedies which could help to bring positive results like: customer relationship management and suitable performance tactic which can help companies in achieving competitive advantage and high customer service delivery (Esther \& Katuse, 2013).

Logan (2000) noted that outsourcing strategy is rarely an easy strategy and create great upheaval and adversely affect logistics performance if handled poorly. Challenges faced by logistics service providers found better solutions which include performance margins for logistics outsourcing and information sharing encouragement mechanisms among others. These remedies were highly supported by 2 of out the 3 company managers. Analysis showed that it was upon working together as parties to achieve greater logistics performance which is being sought of, when all business firms concentrate on their core competences to meet desired results (Hoecht \& Trott, 2006).

\section{Recommendations and Conclusions}

\subsection{Recommendations}

It is imperative to recommend that, innovative ability of an organization is to greater extent reliant upon incremental understanding that was made up for quite long time of experience. This research paper set forward a diverse theoretical study for oil and gas firms that perceived impact of the outsourcing strategy on the logistics performance. The researcher looked at the long and short term gains resulting from the strategy.

Another recommendation to note is that company managers should not only be mindful at minimizing logistics cost while dealing with other companies but to consider factors that bind them. They should be concentrating on employing their company knowledge bases to develop new products or services for the impending ever growing customer needs and meet them more sufficiently. This is accomplished through a technique called customer relationship management. The aim of this technique is to achieve greater customer service delivery through knowing every detail of customer need. Therefore, maintaining old customers while improving on strategies that create new customers, hence competitive advantages. 
In addition to that, company Managers need to assess strategies to find out those tasks that expedite innovativeness and eventually realized projected product or service. This is true because a plan to minimize logistics costs to achieving logistics performance is already thought for.

Oil and gas company managers should always take factors of selecting service providers very seriously in order to create an environment of mutual understanding between two parties involved in business contracts. For example improvement and business support expansion need to be adapted by oil and gas companies to achieve higher customer base.

\subsection{Conclusions}

In conclusion, it has been noted that information asymmetry is likely to occur since the principal companies find it difficult to fully monitor activities provided by the logistics service providers in the long run. However, solutions must be thought for to counteract challenges associated with the strategy so that there is a continuous going concern between the principal company and service providers. This is one way of avoiding conflict interests thereby achieving efficient customer service delivery.

In addition to that, benefit of logistics outsourcing are product of better business dealings that require both principal companies and logistics service providers to make a concrete commitment that will not only last for short time but long term in the process of designing decisions. However the transition of the relationship between the principal and service providers "oil and gas companies and logistics service providers" can only succeed in this business relationship if only transactional purchasing arrangements of doing something approaches true partnership in a third party logistics relationships and proves more an ideal than reality. Some problems like reluctance of buyers to share information with suppliers and trust pledged is lost as result of using outsourcing strategy especially if the terms of contract are not fully stipulated at the time of execution.

\section{Acknowledgements}

This work was supported in part by grants from the Innovation Program of Shanghai Municipal Education Commission (No. 13ZS065), the National Social Science Foundation of China (No. 13CGL057), and the Shanghai Philosophy and Social Science Planning Project (No. 2012BGL006).

\section{References}

Ahimbisibwe, A., Nangoli, S., \& Tusiime, W. (2012). Formal contractual governance mechanisms, contract contingencies, inter-organizational trust, supply opportunism and outsourcing performance. International Journal of Business and Behavioral Sciences, 2(9), 7-20. http://dx.doi.org/10.1037/0033-2909.126.6.910

Belcourt, M. (2006). Outsourcing - The benefits and risks. Human Resources Management Review, 16(2), 269-279. http://dx.doi.org/10.1016/j.hrmr.2006.03.011

Cheong, M. L. F. (2004). Logistics outsourcing and 3PL challenges. Innovation in Manufacturing Systems and Technology. Retrieved from http://hdl.handle.net/1721.1/3908

Chima, C. M. (2007). Supply-chain management issues in the oil and gas industry. Journal of Business \& Economics Research, 5(6), 27-36.

Chopra, S., \& Meindl, P. (2009). Supply Chain Management: Strategy, Planning and Operation. Pearson Prentice Hall.

Cooper, R., \& Kaplan, R. S. (1991). Profit priorities from activity-based costing. Harvard Business Review, 69(3), 130-135.

De Boer, L. J., Gaytan, J., \& Arroyo, P. (2006). A satisficing model of outsourcing, Supply Chain Management: An International Journal, 11(5), 444-455. http://dx.doi.org/10.1108/13598540610682462

Esther, N., \& Katuse, P. (2013). Third party logistics in distribution efficiency delivery for competitive advantage in fast moving consumer goods companies In Kenya. International Journal of Social Sciences and Entrepreneurship. 1(8), 1-12.

Freytag, P. V., Clarke, A. H., \& Evald, M. R. (2012). Reconsidering outsourcing solutions. European Management Journal, 30(2), 99-110. http://dx.doi.org/10.1016/j.emj.2011.11.002

Golooba-Mutebi, F. (2003). Devolution and outsourcing of municipal services in Kampala city, Uganda: An early assessment. Public Administration and Development, 23(5), 405-418. http://dx.doi.org/10.1002/pad.290 
Gray, B., Jones, E. C., Weatherton, Y., Bussey, R. S., \& Armstrong, H. (2013). Utilizing pipeline quality and facility sustainability to optimize crude oil supply chains. International Journal of Supply Chain Management, 2(4), 9-16.

Guasch, J. L., \& Kogan, J. (2001). Inventories in Developing Countries: Levels and Determinants: A Red Flag for Competitiveness and Growth. World Bank Publications.

Hoecht, A., \& Trott, P. (2006). Outsourcing, information leakage and the risk of losing technology-based competencies. European Business Review, 18(5), 395-412. http://dx.doi.org/10.1108/09555340610686967

Hofmann, E., \& Belin, O. (2011). Supply Chain Finance Solutions. Springer-Verlag, Berlin Heidelberg. http://dx.doi.org/10.1007/978-3-642-17566-4

Kenyon, G. N., \& Meixell, M. J. (2011). Success factors and cost management strategies for logistics outsourcing. Journal of Management \& Marketing Research, 7, 1-17.

Lee, Y. H., Jeong, C. S., \& Moon, C. (2012). Advanced planning and scheduling with outsourcing in manufacturing supply chain. Computers and Industrial Engineering, 43(1-2), 351-374. http://dx.doi.org/10.1016/S0360-8352(02)00079-7

Levy, D. L. (1995). International sourcing and supply chain stability. Journal of International Business Studies, 26(2), 343-360. http://dx.doi.org/10.1057/palgrave.jibs.8490177

Logan, M. S. (2000). Using agency theory to design successful outsourcing relationships. International Journal of Logistics Management, 11(2), 21-32.

Mckinnon, A. C. (1999). The outsourcing of logistical activities. Global Logistics and Distribution Planning, 215-234.

Mello, J. E., Stank, T. P., \& Esper, T. L. (2008). A model of logistics outsourcing strategy. Transportation Journal, 47(4), 5-25.

Mohiuddin, M. (2010). Research on offshore outsourcing: A systematic literature review. Journal of International Business Research, 10(1), 57-76.

Mohiuddin, M., \& Su, Z. (2013a). Offshore outsourcing of core and none-core activities and integrated firm-level performance: An empirical analysis of Québec manufacturing SMEs. Journal of 'Management', 16(4), 454-478.

Mohiuddin, M., \& Su, Z. (2013b). Manufacturing small and medium size enterprise's offshore outsourcing and competitive advantage: An exploratory study on Canadian offshoring manufacturing SMEs. The Journal of applied Business Research, 29(4), 1111-1130.

Persson, G., \& Virum, H. (2001). Growth strategies for logistics service providers: A case study. International Journal of Logistics Management, 12(1), 53-64.

Quélin, B., \& Duhamel, F. (2003). Bringing together strategic outsourcing and corporate strategy: Outsourcing motives and risks. European Management Journal, 21(5), 647-661. http://dx.doi.org/10.1016/S0263-2373(03)00113-0

Shepherd, B. (2011). Logistics costs and competitiveness: Measurement and trade policy applications. Transport Support Research Series.

Sink, H. L., \& Langley, C. J. (1997). A managerial framework for the acquisition of third-party logistics services. Journal of Business Logistics, 18(2), 163-189.

Sitek, P., \& Wikarek, J. (2012). Mathematical programming model of cost optimization for supply chain from perspective of logistics provider. Management and Production Engineering Review, 3(2), 49-61. http://dx.doi.org/10.2478/v10270-012-0015-z

Sonmez, A. D., \& Lim, G. J. (2012). A decomposition approach for facility location and relocation problem with uncertain number of future facilities. European Journal of Operational Research, 218(2), 327-339. http://dx.doi.org/10.1016/j.ejor.2011.10.028

Weidenbaum, M. (2005). Outsourcing: Pros and cons. Business Horizons, 48(4), 311-315. http://dx.doi.org/10.1016/j.bushor.2004.11.001

Zhao, X., \&Tang, Q. (2009). Analysis and strategy of the Chinese logistics cost reduction. International Journal of Business and Management, 4(4), 188-191. 
Zhou, J., Li, Z., \& Wang, K. (2013). A multi-objective model for locating fire stations under uncertainty. Advances in Information Sciences and Service Sciences, 5(7), 1184-1191. http://dx.doi.org/10.4156/AISS.vol5.issue7.140

Zhou, J., \& Liu, B. (2003). New stochastic models for capacitated location-allocation problem. Computers and Industrial Engineering, 45(1), 111-125. http://dx.doi.org/10.1016/S0360-8352(03)00021-4

Zhou, J., \& Liu, B. (2007). Modeling capacitated location-allocation problem with fuzzy demands. Computers and Industrial Engineering, 53(3), 454-468. http://dx.doi.org/10.1016/j.cie.2006.06.019

\section{Copyrights}

Copyright for this article is retained by the author(s), with first publication rights granted to the journal.

This is an open-access article distributed under the terms and conditions of the Creative Commons Attribution license (http://creativecommons.org/licenses/by/3.0/). 